\title{
Where are kids getting their empty calories? Stores, schools, and fast food restaurants each play an important role in empty calorie intake among US children in 2009-2010
}

\author{
Jennifer M. Poti ${ }^{*}$ [PhD candidate], \\ Phone: 804-239-9606; Fax: 919-966-9159 \\ Meghan M. Slining, PhD* [Research Assistant Professor], \\ Phone: 919-962-6115; Fax: 919-966-9159 \\ Barry M. Popkin, PhD*, and \\ Phone: 919-966-1732; Fax: 919-966-9159 \\ W.R. Kenan Jr. [Distinguished Professor] \\ Phone: 919-966-1732; Fax: 919-966-9159 \\ Jennifer M. Poti: poti@unc.edu; Meghan M. Slining: slining@email.unc.edu
}

\section{Abstract}

\begin{abstract}
Consumption of empty calories, the sum of energy from added sugar and solid fat, exceeds recommendations, but little is known about where US children obtain these empty calories. The objectives of this study were to compare children's empty calorie consumption from retail food stores, schools, and fast food restaurants; to identify food groups that were top contributors of empty calories from each location; and to determine the location providing the majority of calories for these key food groups. This cross-sectional analysis used data from 3,077 US children aged 2-18 years participating in the 2009-2010 National Health and Nutrition Examination Survey. The empty calorie content of children's intake from stores (33\%), schools (32\%), and fast food restaurants (35\%) was not significantly different in 2009-2010. In absolute terms, stores provided the majority of empty calorie intake $(436 \mathrm{kcal})$. The top contributors of added sugar and solid fat from each location were similar: sugar sweetened beverages (SSBs), grain desserts, and high-fat milk from stores; high-fat milk, grain desserts, and pizza from schools; and SSBs, dairy desserts, french fries, and pizza from fast food restaurants. Schools contributed about $20 \%$ of children's
\end{abstract}

\footnotetext{
(C) 2013 Academy of Nutrition and Dietetics. Published by Elsevier Inc. All rights reserved.

Corresponding author and requests for reprints: Barry M. Popkin, PhD, Carolina Population Center, University of North Carolina, CB \# 8120, University Square, 123 W Franklin St, Chapel Hill, NC 27516-3997, Phone: 919-966-1732, Fax: 919-966-9159/6638, popkin@unc.edu.

Department of Nutrition, Carolina Population Center, University of North Carolina, CB \# 8120, University Square, 123 W. Franklin St, Chapel Hill, NC 27516

Conflict of interest: The authors have no conflicts of interest.

Financial Disclosure: Funding for this study comes from the Robert Wood Johnson Foundation (Grant 70017) and the National Institutes of Health (R01 HL104580, CPC 5 R24 HD050924, and 5T32DK007686-19).

Publisher's Disclaimer: This is a PDF file of an unedited manuscript that has been accepted for publication. As a service to our customers we are providing this early version of the manuscript. The manuscript will undergo copyediting, typesetting, and review of the resulting proof before it is published in its final citable form. Please note that during the production process errors may be discovered which could affect the content, and all legal disclaimers that apply to the journal pertain.
} 
intake of high-fat milk and pizza. In conclusion, these findings support the need for continued efforts to reduce empty calorie intake among US children aimed not just at fast food restaurants, but also at stores and schools. The importance of reformed school nutrition standards was suggested, as prior to their implementation, schools resembled fast food restaurants in their contributions to empty calorie intake.

\section{Keywords}

store; school; fast food; empty calories; dietary intake

\section{Introduction}

The Dietary Guidelines for Americans (DGA), 2010, recommend that both children and adults reduce their intake of calories from solid fat and added sugar, collectively referred to as empty calories. ${ }^{1,2}$ Because solid fat and added sugar contribute calories without providing essential nutrients, excessive consumption of these empty calories has been shown to displace more nutrient-dense foods and drive energy intake above caloric needs. ${ }^{1,3-5}$ Solid fats (discretionary fats which are solid at room temperature) are largely composed of saturated and trans fatty acids, which are associated with increased risk of cardiovascular disease. ${ }^{1,6,7}$ Added sugars are defined as caloric sweeteners added to foods during processing, preparation, or at the table, but excluding natural sugars found in fruit and milk. ${ }^{1}$ In addition to contributing to excessive calorie intake, high consumption of added sugar has been associated with increased body weight and cardiovascular disease risk factors. ${ }^{8-10}$ Therefore, the DGA specify that consumption of empty calories should be limited to 8-19\% of total energy intake, depending on total calorie requirements. ${ }^{1}$

There is great need for policy efforts and environmental changes to help American children meet these DGA recommendations, as $97 \%$ of US children had intake of energy from solid fat and added sugar that exceeded the maximum discretionary calorie allowance in 2001-2004. ${ }^{11,12}$ By 2009-2010, 33\% of children's total energy intake came from empty calories (368 kcal from solid fat and $278 \mathrm{kcal}$ from added sugar). ${ }^{13}$

Despite the substantial contribution of empty calories to total energy intake, little is known about where children obtain these empty calories. Retail food stores, including supermarkets, grocery stores, and convenience stores, provide the majority of overall energy intake for children (69\%); we hereafter refer to all foods and beverages obtained from these locations as store-bought foods. ${ }^{14}$ Schools provide up to $47 \%$ of daily energy intake for participants in the school meals programs. ${ }^{15}$ Consumption of foods and beverages from fast food restaurants (hereafter referred to as fast foods) has increased steadily during recent decades. ${ }^{14,16}$ In 1996, the saturated fat density of foods consumed by children was greatest for foods from schools (14.4\% of total energy intake) and fast food restaurants (13.6\%) and lower for store-bought foods $(11.5 \%) .{ }^{17}$ More recent comparisons of children's intake across locations, as well as any comparison of added sugar and solid fat consumption, are not available. The need for these updated comparisons was identified by a recent review of the dietary effects of eating outside the home. ${ }^{18}$ Previous studies identified sugar sweetened 
beverages (SSBs), grain desserts, whole milk, and pizza as top contributors to empty calorie consumption for children, yet top contributors consumed specifically from stores, schools, and fast food restaurants have not been identified. ${ }^{13,19}$

Thus, the purpose of this study is to compare the role of stores, schools, and fast food restaurants in the intake of empty calories among US children in 2009-2010. This analysis focuses on three research questions: Does empty calorie consumption among US children differ for intake from stores, schools, and fast food restaurants? What foods are the top contributors to added sugar and solid fat intake from each location? For these specific foods, which location provides the majority of calories? Top foods contributing to empty calorie consumption at each location can be targeted by future policy efforts to improve the food environment.

\section{Methods}

\section{Participants}

This analysis studied children aged 2-18 years from the 2009-2010 National Health and Nutrition Examination Survey (NHANES), a cross-sectional survey that uses a complex, multistage, stratified sampling design to provide nationally representative estimates of dietary intake of the civilian, non-institutionalized US population. Details about the survey methodology are available online. ${ }^{20}$

\section{Dietary Data}

NHANES collected two interviewer-administered 24-hour dietary recalls using multiplepass methodology. The first day was collected in person, and the second day was collected 3-10 days later by telephone. Recalls were completed by a proxy respondent for children less than 6 years of age and were proxy-assisted for children ages 6-11.

The calorie content of each food was determined by the US Department of Agriculture (USDA) using the Food and Nutrient Database for Dietary Studies (FNDDS) 5.0. Added sugar and solid fat content was obtained from the USDA's MyPyramid Equivalents Database (MPED) using definitions provided therein (Appendix 1). ${ }^{21}$ Updated MPED databases specific for NHANES 2005-2010 have not been released. Thus, MPED version 2.0 and The Center for Nutrition Policy and Promotion's MPED 2.0 Addendum were used to determine the solid fat and added sugar content of items reported in 2009-2010 using methodology employed both by previous studies and by the National Cancer Institute's Pyramid Servings Database for NHANES III Appendix 1). ${ }^{22-24}$ Empty calories were calculated as the sum of energy from solid fat and added sugar. $1,13,19$

Foods were classified into mutually exclusive, nutritionally meaningful categories (Appendix Table 1) based on the University of North Carolina at Chapel Hill (UNC-CH) food grouping system, which has been described in detail elsewhere. ${ }^{13,25}$

\section{Location}

This analysis defined location as the place where each food or beverage was obtained, as reported by the participant for each recalled item, regardless of the location where the item 
was consumed (e.g., bread and peanut butter purchased from a grocery store, prepared at home as a sandwich, and consumed at school are classified as from a store). These locations were defined by the NHANES Dietary Interviewers Procedures Manual and were grouped into 5 categories: Stores, including supermarkets, grocery stores, and convenience stores; Schools, including school cafeterias and child care centers; Fast Food restaurants, defined by the surveys as any restaurant without a wait staff and including pizza home delivery; Restaurants with wait staff; and Other locations, including vending machines, food/ice cream trucks, foods from other people, foods grown at home, sports/recreation facilities, and community feeding programs. ${ }^{14,26}$ Hereafter, the term "fast food" refers to all items purchased from a fast food restaurant regardless of the item type to be consistent with the conventional definition used by previous studies. ${ }^{18,27}$ Based on the mean percentage of total calories consumed from each location, this analysis focused on stores $(68.7 \%)$, schools (8.5\%), and fast food restaurants $(10.8 \%)$ because restaurants $(4.7 \%)$ represented a small proportion of children's calories and other locations ( $7.2 \%$ collectively) represented a heterogeneous group of locations. Location food consumers are defined as children who consumed any items during the first day of recall obtained from that location.

\section{Analytical Sample}

Only the first day of dietary recall was used in this analysis because the MPED 2.0 Addendum includes only new foods reported on recall Day 1 but not Day 2, and NHANES analytic guidelines recommend using Day 1 only to generate group mean intake. ${ }^{28}$ Children were excluded when missing the location for any item $(n=18)$ or when consuming items for which empty calorie content could not be estimated $(n=29)$ for a final sample of 3,077 children. Sociodemographic characteristics of this sample are provided in Appendix Table 2.

\section{Statistical Analysis}

Empty calorie consumption from stores, schools, and fast food restaurants was compared in absolute and relative terms. For each location, the percentage of location-specific nutrient intake provided by each food group was ranked to identify the food groups providing the largest contributions to empty calorie, added sugar, or solid fat intake for each location; analyses were performed separately for intake from stores, schools, or fast food restaurants. For these food groups, the percentage of total calories obtained from each location was determined in order to identify the location providing the majority of calories. Survey commands within Stata (version 12, 2011, StataCorp) were used to take into account complex survey design and sample weights which incorporate differential probabilities of selection, nonresponse, and noncoverage. Locations were compared using $t$ tests and $P<$ 0.05 with Bonferroni correction for multiple comparisons was considered significant. This secondary data analysis was deemed exempt by the UNC-CH Institutional Review Board.

\section{Results and Discussion}

The relative contributions of empty calories to total intake from stores (33\%), schools (32\%), and fast food restaurants (35\%) were not significantly different (Figure 1). Average empty calorie intake from each location greatly surpassed recommendations, which helps explain why the total intake of almost all US children exceeds these guidelines. ${ }^{11,12}$ The 
percentage of calories from added sugar was higher for store foods (15\%) compared to school food (10\%) or fast food (10\%). The relative contribution from solid fat was largest for fast food (24\%), but significantly higher for school foods (22\%) compared to store foods $(18 \%)$.

However, in absolute terms, store-bought foods contributed significantly more empty calories (436 kcal/d), added sugar (195 kcal/d), and solid fat (241 kcal/d) per capita than either school foods or fast foods (Figure 1). These per capita estimates reflect the substantially larger percentage of children who consumed store-bought foods on a single given day (99\%) compared to the percentage consuming fast food (32\%) or school food $(24 \%)$.

The food groups providing the greatest contributions to empty calorie, added sugar, and solid fat intake differed by location, yet notable similarities occurred (Table 1 and Appendix Table 3). High-fat milk was the \#1 contributor of both added sugar and solid fat for schools and also made a substantial contribution to solid fat intake from stores. SSBs were the largest contributor of added sugar from stores and fast food restaurants, but played a much lesser role at schools. Pizza was an important contributor of solid fat for both schools and fast food restaurants. Grain desserts were main contributors of added sugar and solid fat from both stores and schools. This substantial overlap across locations might explain the similarity in overall empty calorie content of foods consumed from stores, schools, and fast food restaurants.

Several major contributors of solid fat were the same at schools and fast food restaurants, including pizza, sandwiches, and Mexican dishes. These findings are consistent with previous analysis showing that pre-prepared fast-food-like items, such as pizza, sandwiches with breaded chicken, tacos, and burritos, were major sources of saturated fat in school lunches. ${ }^{29}$ However, in contrast to fast food restaurants, SSBs contributed only $5.3 \%$ of the added sugar consumed from schools (Appendix Table 3). In agreement, previous studies found that, by 2004-2005, only 13.8\% of children obtained and consumed SSBs at school, and by 2008 , full-calorie soft drinks were rarely available. ${ }^{15,30}$

Stores provided the majority of calorie intake for $3 / 4$ of the food groups identified as top contributors of empty calories, added sugar, or solid fat at any location (Appendix Table 4). Notably, stores were the predominant location where SSBs were obtained, providing over $70 \%$ of SSB calories. These findings help explain why increased access to supermarkets is not consistently associated with healthier diets among children. ${ }^{31-34}$

Fast food restaurants provided the majority of intake only for french fries. Although previous studies found that fast food consumers have higher intake of SSBs, pizza, and hamburgers compared to non-consumers, our findings imply that these items are consumed not just at fast food restaurants but also largely from stores and schools. ${ }^{35-38}$

Schools provided about one-fifth of calories from pizza, high-fat milk, and low-fat milk. In agreement, a recent evaluation of school meals in 2010 found that pizza was available most or every day for $98 \%$ of secondary school students and high-fat or flavored milk was available for over $60 \%$ of students. ${ }^{39}$ 


\section{Implications}

Previous studies of total consumption by children identified pizza, grain desserts, and whole milk as top contributors of solid fat, and SSBs and grain desserts as top contributors of added sugar. ${ }^{13,19}$ Our findings confirm these results, but further clarify that these food groups were important contributors of empty calories only for specific locations. Thus, strategies to reduce empty calorie intake might vary for stores, schools, and fast food restaurants.

At stores, several food manufacturers and retailers have made voluntary pledges to improve the nutritional content of packaged foods through product reformulations and introduction of lower-calorie products. ${ }^{40-42}$ Our results suggest key contributors of empty calories from stores that these efforts could modify, such as SSBs, grain desserts, and candy.

Our data was collected prior to implementation of the Healthy, Hunger-Free Kids Act of 2010, and updated USDA nutrition standards for school meals will potentially reduce empty calorie intake. ${ }^{43-45}$ Our results can help identify foods to target as schools implement these new standards: high-fat flavored milk, grain desserts, and pizza. In addition, our findings can aid policy makers as they establish standards for competitive foods.

One potentially important change to the school nutrition standards will limit availability to only $1 \%$ plain milk and fat-free plain or flavored milk. ${ }^{45}$ Our results support the need for this change, as high-fat milk was the \#1 contributor of both added sugar and solid fat at school, and schools provided a substantial portion of children's high-fat milk intake. Our results are consistent with previous school-based studies finding that $56.3 \%$ of school milk was chocolate or flavored. ${ }^{46}$ In addition, only one-third of US schools offered only lower-fat milks in 2009-2010.47

The top contributors of empty calories from fast food restaurants were SSBs, dairy desserts, french fries, and pizza, items that are widely offered and consumed by children at fast food restaurants. ${ }^{48,49}$ Thus, these items could be targeted by public health efforts aimed at fast food restaurants, including recent legislation requiring menu board labeling of nutrition content, voluntary efforts by fast food restaurants to make more healthful side items the default in kid's meals, and the National Restaurant Association's Kids LiveWell program. ${ }^{50-52}$

\section{Limitations}

Because an updated MPED is not available for NHANES 2009-2010, added sugar and solid fat were determined using MPED 2.0 and the MPED Addendum. To examine the impact of these methods, two sensitivity analyses were performed (Appendix 1). Conclusions did not differ from the results presented here, confirming the robustness of our results. NHANES does not distinguish among different store types, although supermarkets tend to have more fresh produce and greater variety compared to smaller food stores, such as convenience stores. ${ }^{31,32}$ Some studies suggest that dietary misreporting varies with a child's age and weight status and that unhealthy foods are selectively underreported; however, there is no evidence of differential misreporting by location. ${ }^{53,54}$ 


\section{Conclusions}

Foods consumed by children from stores and schools were not significantly lower in empty calorie content than fast foods in 2009-2010. This analysis therefore supports the conclusion of several previous studies that efforts to reduce children's consumption of empty calories must be made across multiple locations - not just at fast food restaurants, but also at stores and schools. ${ }^{15,55,56}$ Our findings identify areas for potential improvement and can inform future strategies to address specific locations and foods which are contributing to excessive consumption of empty calories by US children. In particular, high-fat flavored milk, grain desserts, and pizza were identified as top contributors to empty calorie intake from schools, and these foods should be targeted as the new federal nutrition standards for school meals are implemented and as the standards for competitive foods are finalized. Future studies should evaluate voluntary efforts by food manufacturers and retailers to improve the nutritional quality of packaged foods sold at stores, progress made by new federal nutrition standards at schools, and the effectiveness of fast food menu board labeling.

\section{Acknowledgments}

We thank the Robert Wood Johnson Foundation (Grant 70017) and the National Institutes of Health (R01 HL104580, CPC 5 R24 HD050924, and 5T32DK007686-19) for financial support. We also thank Dr. Phil Bardsley for exceptional assistance with data management and programming and Ms. Frances L. Dancy for administrative assistance.

\section{Appendix 1}

Foods were recorded as consumed using discrete foodcodes. The nutrient composition (total calories, total fat, and total sugar) of each food was determined by the US Department of Agriculture (USDA) using the Food and Nutrient Database for Dietary Studies (FNDDS) 5.0. Because FNDDS does not include added sugar and solid fat content, these values were obtained from the USDA's MyPyramid Equivalents Database (MPED). ${ }^{21}$ MPED version 2.0 measures discretionary solid fats as fats that are solid at room temperature and in excess of the allowable amount found in the leanest/lowest fat form of meat, poultry, fish, eggs, beans, and milk and in the basic/natural forms of grains, fruits, and vegetables. ${ }^{21}$ MPED version 2.0 defined added sugar as sugar used in processed and prepared foods, sugar eaten separately, or sugar added to foods at the table, but excluding naturally occurring sugars in milk (lactose) or fruit (fructose). ${ }^{21}$ This definition of added sugar does not include fruit juice concentrate used as an ingredient or sugar substitutes. ${ }^{21}$ Multi-ingredient foods are disaggregated into their basic ingredients, and the discretionary solid fat and added sugar content is calculated as the sum of solid fat or added sugar in each ingredient using a recipe retention factor method. ${ }^{21}$

Foodcodes used by NHANES 2003-2004 can be directly linked to MPED version 2.0. However, updated MPED databases specific for NHANES 2005-2010 have not been released. Thus, MPED version 2.0 and The Center for Nutrition Policy and Promotion's (CNPP) MPED 2.0 Addendum were used to estimate the empty calorie content of items reported in 2009-2010 using methodology employed both by previous studies and by the National Cancer Institute's Pyramid Servings Database for NHANES III. ${ }^{22-24}$ Conversion 
factors of $9 \mathrm{kcal} / \mathrm{g}$ for solid fat and $16 \mathrm{kcal} / \mathrm{tsp}$ for added sugar were used, and empty calories were calculated as the sum of energy from solid fat and added sugar. ${ }^{1,13,19}$

Most foodcodes (89\%) reported in NHANES 2009-2010 were also used for NHANES 2003-2004 so that empty calorie content was obtained directly from MPED. For these exact foodcode matches, the ratio of solid fat to total fat and the ratio of added sugar to total sugar in MPED were applied to the total fat and total sugar content from FNDDS for these same foodcodes in 2009-2010. Applying these ratios allows more accurate estimation of empty calories by incorporating FNDDS updates to total fat and total sugar information that reflect changes in the food supply between 2003-2004 and 2009-2010. Approximately 9\% of foodcodes reported in 2009-2010 were newly introduced in NHANES 2005-2008; these have exact added sugar and solid fat content provided by The CNPP MPED 2.0 Addendum, which uses USDA's methodology. ${ }^{22}$ The remaining $2 \%$ of foodcodes were newly introduced in NHANES 2009-2010. Of these 69 foodcodes, 44 were matched to items with similar foodcodes and food descriptions. For example, "CASHEW NUTS, DRY ROASTED, WITHOUT SALT" was reported in 2009-2010 and matched to "CASHEW NUTS, DRY ROASTED" in MPED. Matches could not be found for the remaining 25 foodcodes, so the children consuming these foods $(n=29)$ were excluded from this analysis.

To examine the impact of these estimations, two sensitivity analyses were performed: 1) including children $(n=29)$ who consumed foods that were not estimable but excluding only those specific food items and 2) directly using MPED values rather than applying ratios from MPED to FNDDS total sugar and fat. Conclusions did not differ from the results presented here, confirming the robustness of our results to these estimations.

\section{Appendix Table 1}

Description of food grouping system used to identify top food groups contributing to empty calorie intake among US children

\begin{tabular}{|l|l|}
\hline Food Group Name & Food Group Description \\
\hline Cheese & Includes all cheeses. \\
\hline Yogurt & Includes refrigerated yogurts. \\
\hline Other dairy products & $\begin{array}{l}\text { Includes sour cream, whipped topping, cream, condensed milk, and } \\
\text { evaporated milk. }\end{array}$ \\
\hline Meat and meat dishes & $\begin{array}{l}\text { Includes beef, pork, lamb, veal, game, and their organ meats (plain, breaded, } \\
\text { and/or with sauce) and meat dishes. }\end{array}$ \\
\hline Chicken and chicken dishes & $\begin{array}{l}\text { Includes chicken, turkey, other birds, and their organ meats (plain, breaded, } \\
\text { and/or with sauce or skin) and poultry dishes. }\end{array}$ \\
\hline $\begin{array}{l}\text { Processed meat and processed meat } \\
\text { dishes }\end{array}$ & $\begin{array}{l}\text { Includes processed meat and poultry; meat products cured, salted, smoked or } \\
\text { preserved with nitrate; and processed meat dishes. }\end{array}$ \\
\hline Fish and fish dishes & $\begin{array}{l}\text { Includes fish and shellfish (plain, breaded, and/or with sauce) and fish/ } \\
\text { shellfish dishes. }\end{array}$ \\
\hline Legumes and meat substitutes & Includes legumes, legume dishes, and meat substitutes. \\
\hline Eggs & Includes eggs and egg dishes. \\
\hline Nuts and seeds & Includes nuts, nut butters, and seeds. \\
\hline
\end{tabular}




\begin{tabular}{|c|c|}
\hline Food Group Name & Food Group Description \\
\hline Breads and rolls & Includes yeast breads and rolls, plain or as toast. \\
\hline Quick breads & Includes breads not leavened with yeast. \\
\hline Ready-to-eat (RTE) cereals & Includes ready-to-eat cereals. \\
\hline Sandwiches & Includes sandwiches, rolls, wraps, breakfast sandwiches, and hot dogs. \\
\hline Hamburgers & $\begin{array}{l}\text { Includes hamburgers, cheeseburgers, and bacon cheeseburgers, both pre- } \\
\text { prepared and home-cooked from ground meat. }\end{array}$ \\
\hline Mexican dishes & Includes tortilla-based Mexican dishes. \\
\hline Pasta and pasta dishes & Includes pasta, noodles, and pasta-based dishes. \\
\hline Grains and grain dishes & Includes grains and grain dishes. \\
\hline Pizza & Includes all types of pizzas and calzones, including frozen pizza. \\
\hline Fruit & Includes fresh, frozen, canned, or dried fruit. \\
\hline Vegetables & $\begin{array}{l}\text { Includes fresh, frozen, or canned non-starchy vegetables (plain, with breading } \\
\text { with added fat in cooking, and/or sauce). }\end{array}$ \\
\hline Starchy vegetables & $\begin{array}{l}\text { Includes starchy vegetables (excluding fried potatoes) and all vegetable } \\
\text { dishes. }\end{array}$ \\
\hline French fries & Includes french fries and fried potatoes. \\
\hline Fats and oils & Includes fats from an animal or plant source. \\
\hline Salad dressings & Includes salad dressings. \\
\hline Sauces and condiments & Includes sauces and condiments. \\
\hline Grain desserts & Includes cookies, pastries, cakes, pies, and cereal/granola bars. \\
\hline Candy & Includes candy, chocolate, and sweet snacks. \\
\hline Dairy desserts & Includes dairy-based desserts. \\
\hline Sweeteners & Includes sugars, sweeteners, syrups, jellies, and toppings. \\
\hline Salty snacks & Includes savory salty snacks. \\
\hline Dips and spreads & Includes dips and spreads. \\
\hline Soups and stews & Includes broths, soups and stews (homemade, instant, and ready-to-eat). \\
\hline Frozen meals & Includes frozen entrées, dinners, or breakfast meals. \\
\hline Baby food and formula & Includes infant formulas, baby foods, and toddler foods. \\
\hline Water & Includes tap water, plain bottled water, flavored waters, and carbonated water. \\
\hline Coffee and tea & $\begin{array}{l}\text { Includes coffee and tea (combined with milk, cream, and/or sweeteners) and } \\
\text { coffee beverages. }\end{array}$ \\
\hline Sugar sweetened beverages (SSBs) & $\begin{array}{l}\text { Includes sodas, fruit drinks, sports drinks, and energy drinks (regular, sugar- } \\
\text { free, and diet). }\end{array}$ \\
\hline Fruit juice & Includes fruit juice (100\% juice and not $100 \%$ juice). \\
\hline Vegetable juice & Includes vegetable juice (100\% juice and not $100 \%$ juice). \\
\hline Milk - low-fat & Includes nonfat and $1 \%$ milk (plain, chocolate, or flavored). \\
\hline Milk - high-fat & Includes whole and $2 \%$ milk (plain, chocolate, or flavored). \\
\hline Milk shakes & Includes milk-, soy-, and yogurt-based beverages. \\
\hline Meal replacement beverages & Includes milk replacement beverages. \\
\hline Alcohol & Includes beer, wine, liquor, and mixed alcoholic beverages. \\
\hline Other beverages & Includes all other beverages such as horchata, rice beverages, and atole. \\
\hline
\end{tabular}




\section{Appendix Table 2}

\section{Sociodemographic characteristics of consumers from each location (stores, schools, and fast food restaurants) among US children aged 2-18 years, NHANES 2009-2010 ${ }^{a}$}

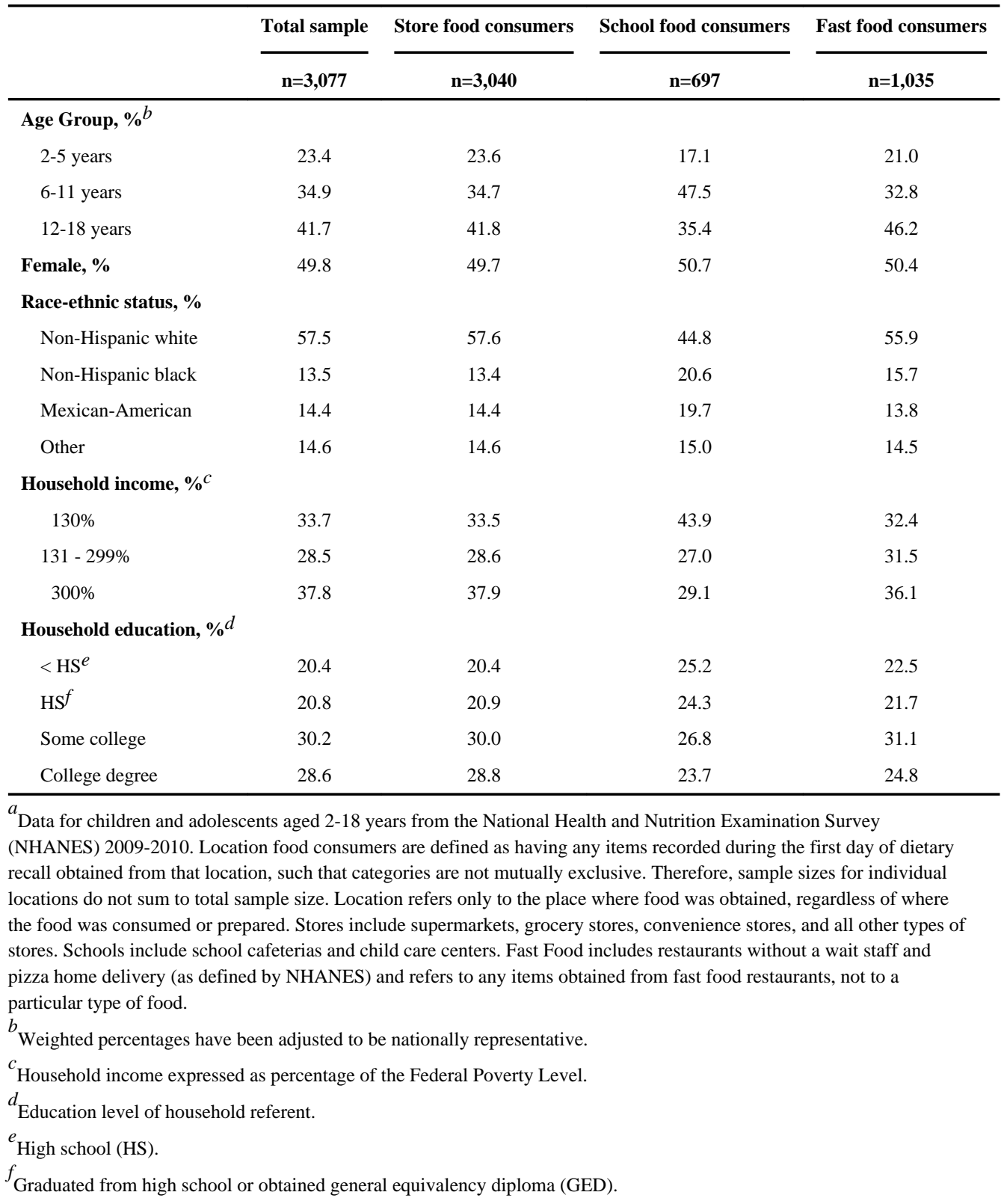




\title{
Appendix Table 4
}

\author{
Mean intake and percentage of calories from each \\ location for food groups identified as top contributors of \\ empty calories, added sugar, or solid fat ${ }^{a}$ among US \\ children aged 2-18 years, 2009-2010
}

\begin{tabular}{|c|c|c|c|c|c|c|}
\hline \multirow[b]{3}{*}{ Food Group } & \multirow{3}{*}{$\begin{array}{c}\text { Per Capita } \\
\text { Food Group } \\
\text { Intake }^{c}\end{array}$} & \multicolumn{5}{|c|}{ Percentage of Food Group Intake from Each Location ${ }^{d}$} \\
\hline & & Store $^{e}$ & School & Fast Food & Restaurant & Other \\
\hline & & $\underset{\text { SE }}{\text { Mean } \%} \pm$ & $\begin{array}{r}\text { Mean } \% \pm \\
\text { SE }\end{array}$ & $\begin{array}{r}\text { Mean } \% \pm \\
\text { SE }\end{array}$ & $\begin{array}{r}\text { Mean } \% \pm \\
\text { SE }\end{array}$ & $\begin{array}{r}\text { Mean } \% \pm \\
\text { SE }\end{array}$ \\
\hline Sandwiches & $186 \pm 11.4$ & $65.9 \pm 1.7^{*}$ & $10.4 \pm 1.5$ & $17.4 \pm 1.2$ & $1.1 \pm 0.4$ & $5.2 \pm 0.8$ \\
\hline Grain desserts & $134 \pm 5.4$ & $76.2 \pm 1.7^{*}$ & $6.4 \pm 1.2$ & $1.5 \pm 0.4$ & $1.8 \pm 0.6$ & $14.2 \pm 1.0$ \\
\hline $\operatorname{SSB}^{f} f$ & $132 \pm 7.4$ & $71.6 \pm 1.6^{*}$ & $1.1 \pm 0.3$ & $10.3 \pm 0.9$ & $6.7 \pm 0.8$ & $10.2 \pm 1.1$ \\
\hline Milk - high-fat $g$ & $123 \pm 5.0$ & $73.2 \pm 1.5^{*}$ & $21.6 \pm 1.3$ & $1.4 \pm 0.6$ & $1.9 \pm 0.6$ & $1.9 \pm 0.5$ \\
\hline Pizza & $105 \pm 12.8$ & $32.8 \pm 3.7$ & $20.4 \pm 3.2$ & $31.3 \pm 3.6$ & $8.1 \pm 2.0$ & $7.3 \pm 2.3$ \\
\hline Pasta dishes & $96 \pm 5.7$ & $81.1 \pm 2.2^{*}$ & $5.0 \pm 1.1$ & $2.3 \pm 0.9$ & $6.0 \pm 1.4$ & $5.7 \pm 1.4$ \\
\hline Mexican dishes & $77 \pm 8.8$ & $60.7 \pm 5.7^{*}$ & $8.0 \pm 2.2$ & $19.3 \pm 6.0$ & $4.8 \pm 1.4$ & $7.2 \pm 1.9$ \\
\hline Candy & $59 \pm 3.9$ & $70.7 \pm 3.1^{*}$ & $1.8 \pm 0.7$ & $0.6 \pm 0.3$ & $1.9 \pm 0.6$ & $25.0 \pm 3.0$ \\
\hline Quick breads & $58 \pm 4.3$ & $72.7 \pm 4.6^{*}$ & $9.1 \pm 2.4$ & $5.3 \pm 2.4$ & $8.1 \pm 2.0$ & $4.7 \pm 1.4$ \\
\hline RTE cereal & $56 \pm 4.0$ & $93.6 \pm 1.1^{*}$ & $4.7 \pm 1.0$ & $0.0 \pm 0.0$ & $0.0 \pm 0.0$ & $1.7 \pm 0.4$ \\
\hline Dairy desserts & $49 \pm 3.3$ & $61.2 \pm 6.3^{*}$ & $4.3 \pm 1.3$ & $15.2 \pm 3.1$ & $4.6 \pm 1.0$ & $14.9 \pm 3.5$ \\
\hline Hamburgers & $45 \pm 4.7$ & $22.4 \pm 5.4$ & $16.1 \pm 4.0$ & $45.8 \pm 7.5$ & $12.5 \pm 3.2$ & $3.3 \pm 1.3$ \\
\hline Milk - low-fat & $42 \pm 3.2$ & $79.9 \pm 3.1^{*}$ & $17.3 \pm 2.8$ & $0.7 \pm 0.4$ & $0.2 \pm 0.1$ & $1.8 \pm 0.5$ \\
\hline French fries & $42 \pm 4.1$ & $17.3 \pm 3.0$ & $5.2 \pm 1.6$ & $61.1 \pm 2.3^{*}$ & $11.8 \pm 1.5$ & $4.6 \pm 1.0$ \\
\hline Coffee and tea & $18 \pm 2.8$ & $82.5 \pm 3.6^{*}$ & $1.4 \pm 0.8$ & $7.3 \pm 1.9$ & $3.9 \pm 1.5$ & $4.8 \pm 1.2$ \\
\hline Milk shakes & $13 \pm 2.4$ & $54.3 \pm 11.2$ & $0.0 \pm 0.0$ & $36.0 \pm 9.5$ & $5.6 \pm 3.2$ & $4.1 \pm 4.3$ \\
\hline
\end{tabular}

* Percentage of food group intake is significantly higher for noted location in all pair-wise comparisons of locations, $\mathrm{p}<0.05$ after Bonferroni correction. For food groups with no notation, no single location was significantly higher than each of the four other locations.

${ }^{a}$ Includes any food group ranked among the top five contributors of empty calories (the sum of energy from solid fat and added sugar), added sugar, or solid fat from any location (determined as food groups with the highest percentage contribution to intake of empty calories, added sugar, or solid fat from each location). $b$ $b$ Data for children and adolescents aged 2-18 years from the National Health and Nutrition Examination Survey (NHANES) 2009-2010. Values are mean \pm standard error (SE).

${ }^{c}$ Mean per capita food group intake (including both consumers and non-consumers of each food group) from all locations combined. For all food groups, mean total energy intake was $1907 \mathrm{kcal}$.

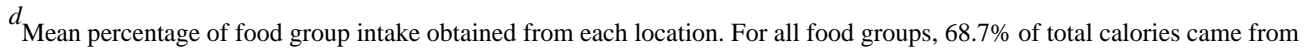
stores, $8.5 \%$ from schools, $10.8 \%$ from fast food restaurants, $4.7 \%$ from restaurants, and $7.2 \%$ from all other locations.

${ }^{e}$ Locations refer only to the place where food was obtained, regardless of where the food was consumed or prepared. Stores include supermarkets, grocery stores, convenience stores, and all other types of stores. Schools include school cafeterias and child care centers. Fast Food includes restaurants without a wait staff and pizza home delivery (as defined by NHANES) and refers to any items obtained from fast food restaurants, not to a particular type of food. Restaurant includes restaurants with wait staff. Other locations include vending machines, food/ice cream trucks, foods from other people, foods grown at home, sports/recreation facilities, and community feeding programs.

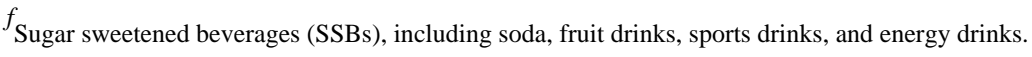




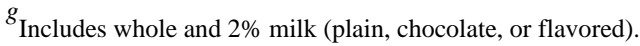

\section{References}

1. US Department of Agriculture, US Department of Health and Human Services. Dietary Guidelines for Americans, 2010. Washington, DC: US Government Printing Office; 2010.

2. Dietary Guidelines Advisory Committee. Report of the Dietary Guidelines Advisory Committee on the Dietary Guidelines for Americans, 2010, to the Secretary of Agriculture and the Secretary of Health and Human Services. Washington, DC: US Department of Agriculture, Agricultural Research Service; 2010.

3. Taveras EM, Berkey CS, Rifas-Shiman SL, et al. Association of consumption of fried food away from home with body mass index and diet quality in older children and adolescents. Pediatrics. 2005; 116(4):e518-524. [PubMed: 16199680]

4. Kant AK. Reported consumption of low-nutrient-density foods by American children and adolescents: nutritional and health correlates, NHANES III, 1988 to 1994. Arch Pediatr Adolesc Med. 2003; 157(8):789-796. [PubMed: 12912785]

5. Templeton SB, Marlette MA, Panemangalore M. Competitive foods increase the intake of energy and decrease the intake of certain nutrients by adolescents consuming school lunch. J Am Diet Assoc. 2005; 105(2):215-220. [PubMed: 15668677]

6. Mozaffarian D, Katan MB, Ascherio A, Stampfer MJ, Willett WC. Trans fatty acids and cardiovascular disease. N Engl J Med. 2006; 354(15):1601-1613. [PubMed: 16611951]

7. Astrup A, Dyerberg J, Elwood P, et al. The role of reducing intakes of saturated fat in the prevention of cardiovascular disease: where does the evidence stand in 2010? Am J Clin Nutr. 2011; 93(4): 684-688. [PubMed: 21270379]

8. Vartanian LR, Schwartz MB, Brownell KD. Effects of soft drink consumption on nutrition and health: a systematic review and meta-analysis. Am J Public Health. 2007; 97(4):667-675. [PubMed: 17329656]

9. Welsh JA, Sharma A, Cunningham SA, Vos MB. Consumption of added sugars and indicators of cardiovascular disease risk among US adolescents. Circulation. 2011; 123(3):249-257. [PubMed: 21220734]

10. Welsh JA, Sharma A, Abramson JL, Vaccarino V, Gillespie C, Vos MB. Caloric sweetener consumption and dyslipidemia among US adults. JAMA. 2010; 303(15):1490-1497. [PubMed: 20407058]

11. Kirkpatrick SI, Dodd KW, Reedy J, Krebs-Smith SM. Income and race/ethnicity are associated with adherence to food-based dietary guidance among US adults and children. J Acad Nutr Diet. 2012; 112(5):624-635 e626. [PubMed: 22709767]

12. Krebs-Smith SM, Guenther PM, Subar AF, Kirkpatrick SI, Dodd KW. Americans do not meet federal dietary recommendations. J Nutr. 2010; 140(10):1832-1838. [PubMed: 20702750]

13. Slining MM, Popkin BM. Trends in intakes and sources of solid fats and added sugars among U.S. children and adolescents: 1994-2010. Pediatr Obes. 2013

14. Poti JM, Popkin BM. Trends in energy intake among US children by eating location and food source, 1977-2006. J Am Diet Assoc. 2011; 111(8):1156-1164. [PubMed: 21802561]

15. Briefel RR, Crepinsek MK, Cabili C, Wilson A, Gleason PM. School food environments and practices affect dietary behaviors of US public school children. J Am Diet Assoc. 2009; 109(2 Suppl):S91-107. [PubMed: 19166677]

16. Nielsen SJ, Siega-Riz AM, Popkin BM. Trends in food locations and sources among adolescents and young adults. Prev Med. 2002; 35(2):107-113. [PubMed: 12200094]

17. Guthrie JF, Lin BH, Frazao E. Role of food prepared away from home in the American diet, 1977-78 versus 1994-96: changes and consequences. J Nutr Educ Behav. 2002; 34(3):140-150. [PubMed: 12047838]

18. Lachat C, Nago E, Verstraeten R, Roberfroid D, Van Camp J, Kolsteren P. Eating out of home and its association with dietary intake: a systematic review of the evidence. Obes Rev. 2012; 13(4): 329-346. [PubMed: 22106948] 
19. Reedy J, Krebs-Smith SM. Dietary sources of energy, solid fats, and added sugars among children and adolescents in the United States. J Am Diet Assoc. 2010; 110(10):1477-1484. [PubMed: 20869486]

20. US Department of Agriculture, Agricultural Research Service, Beltsville Human Nutrition Research Center, Food Surveys Research Group, and US Department of Health and Human Services, Centers for Disease Control and Prevention, National Center for Health Statistics. [Accessed September 2012] National Health and Nutrition Examination Survey 2009-2010. http:// www.cdc.gov/nchs/nhanes/nhanes2009-2010/nhanes09_10.htm

21. Bowman, S.; Friday, J.; Moshfegh, A. MyPyramid Equivalents Database, 2.0 for USDA Survey Foods, 2003-2004. Beltsville, MD: US Department of Agriculture (USDA), Agricultural Research Service, Beltsville Human Nutrition Research Center, Food Surveys Research Group; 2008.

22. Koegel, K.; Kuczynski, K. Center for Nutrition Policy and Promotion Addendum to the MyPyramid Equivalents Database 2.0. Alexandria, VA: USDA Center for Nutrition Policy and Promotion, Nutrition Guidance and Analysis Division; 2011. http://www.cnpp.usda.gov/ OtherProjects.htm [Accessed July 2012]

23. Welsh JA, Sharma AJ, Grellinger L, Vos MB. Consumption of added sugars is decreasing in the United States. Am J Clin Nutr. 2011; 94(3):726-734. [PubMed: 21753067]

24. National Cancer Institute, US National Institutes of Health. Documentation for the Pyramid Servings Database for NHANES III. 2010. http://riskfactor.cancer.gov/pyramid/documentation/

25. Popkin BM, Haines PS, Siega-riz AM. Dietary patterns and trends in the United States: the UNCCH approach. Appetite. 1999; 32(1):8-14. [PubMed: 9989908]

26. US Department of Agriculture, Agricultural Research Service, Beltsville Human Nutrition Research Center, Food Surveys Research Group, and US Department of Health and Human Services, Centers for Disease Control and Prevention (CDC), National Center for Health Statistics. [Accessed January 2013] National Health and Nutrition Examination Survey 2009-2010 MEC Inperson Dietary Interviewers Procedure Manual. http://www.cdc.gov/nchs/nhanes/ nhanes2009-2010/current_nhanes_09_10.htm

27. Rosenheck R. Fast food consumption and increased caloric intake: a systematic review of a trajectory towards weight gain and obesity risk. Obes Rev. 2008; 9(6):535-547. [PubMed: 18346099]

28. US Department of Agriculture, Agricultural Research Service, Beltsville Human Nutrition Research Center, Food Surveys Research Group, and US Department of Health and Human Services, Centers for Disease Control and Prevention (CDC), National Center for Health Statistics. [Accessed March 2012] NHANES Dietary Web Tutorial. http://www.cdc.gov/nchs/tutorials/ Dietary/Basic/PopulationMeanIntakes/intro.htm

29. Crepinsek MK, Gordon AR, McKinney PM, Condon EM, Wilson A. Meals offered and served in US public schools: do they meet nutrient standards? J Am Diet Assoc. 2009; 109(2 Suppl):S3143. [PubMed: 19166671]

30. Johnston, L.; O'Malley, P.; Terry-McElrath, Y.; Colabianchi, N. School Policies and Practices to Improve Health and Prevent Obesity: National Secondary School Survey Results, School Years 2006-07 and 2007-08. Vol. 1. Ann Arbor, MI: Bridging the Gap, Institute for Social Research; 2011.

31. Bodor JN, Rose D, Farley TA, Swalm C, Scott SK. Neighbourhood fruit and vegetable availability and consumption: the role of small food stores in an urban environment. Public Health Nutr. 2008; 11(4):413-420. [PubMed: 17617930]

32. Larson N, Story M. A review of environmental influences on food choices. Ann Behav Med. 2009; 38(1):S56-73. [PubMed: 19802648]

33. Timperio A, Ball K, Roberts R, Campbell K, Andrianopoulos N, Crawford D. Children's fruit and vegetable intake: associations with the neighbourhood food environment. Prev Med. 2008; 46(4): 331-335. [PubMed: 18164753]

34. He M, Tucker P, Irwin JD, Gilliland J, Larsen K, Hess P. Obesogenic neighbourhoods: the impact of neighbourhood restaurants and convenience stores on adolescents' food consumption behaviours. Public Health Nutr. 2012; 15(12):2331-2339. [PubMed: 22390896] 
35. Bowman SA, Gortmaker SL, Ebbeling CB, Pereira MA, Ludwig DS. Effects of fast-food consumption on energy intake and diet quality among children in a national household survey. Pediatrics. 2004; 113(1 Pt 1):112-118. [PubMed: 14702458]

36. French SA, Story M, Neumark-Sztainer D, Fulkerson JA, Hannan P. Fast food restaurant use among adolescents: associations with nutrient intake, food choices and behavioral and psychosocial variables. Int J Obes Relat Metab Disord. 2001; 25(12):1823-1833. [PubMed: 11781764]

37. Powell LM, Nguyen BT. Fast-Food and Full-Service Restaurant Consumption Among Children and Adolescents: Effect on Energy, Beverage, and Nutrient Intake. Arch Pediatr Adolesc Med. 2012:1-7.

38. Paeratakul S, Ferdinand DP, Champagne CM, Ryan DH, Bray GA. Fast-food consumption among US adults and children: dietary and nutrient intake profile. J Am Diet Assoc. 2003; 103(10):13321338. [PubMed: 14520253]

39. Johnston, L.; O'Malley, P.; Terry-McElrath, Y.; Colabianchi, N. School Policies and Practices to Improve Health and Prevent Obesity: National Secondary School Survey Results, School Years 2006-07 and 2009-10. Vol. 2. Ann Arbor, MI: Bridging the Gap, Survey Research Center, Institute for Social Research; 2012.

40. Healthy Weight Commitment Foundation. [Accessed December 2012] Food and Beverage Manufacturers Pledging to Reduce Annual Calories by 1.5 Trillion by 2015. 2010. http:// www.healthyweightcommit.org/news/Reduce_Annual_Calories/

41. Slining MM, Ng SW, Popkin BM. Food companies' calorie-reduction pledges to improve U.S. diet. Am J Prev Med. 2013; 44(2):174-184. [PubMed: 23332336]

42. Walmart. [Accessed December 2012] Walmart Launches Major Initiative to Make Food Healthier and Healthier Food More Affordable. 2011. http://news.walmart.com/news-archive/2011/01/20/ walmart-launches-major-initiative-to-make-food-healthier-healthier-food-more-affordable

43. Healthy, Hunger-Free Kids Act of 2010, Public Law No 111-296. 2010

44. French SA, Story M. Commentary on Nutrition Standards in the National School Lunch and Breakfast Programs. Arch Pediatr Adolesc Med. 2012:1-2.

45. Food and Nutrition Service, US Department of Agriculture. Nutrition standards in the National School Lunch and School Breakfast Programs. Final rule. Fed Regist. 2012; 77(17):4088-4167. [PubMed: 22359796]

46. O'Toole TP, Anderson S, Miller C, Guthrie J. Nutrition services and foods and beverages available at school: results from the School Health Policies and Programs Study 2006. J Sch Health. 2007; 77(8):500-521. [PubMed: 17908105]

47. Turner L, Chaloupka FJ. Slow progress in changing the school food environment: nationally representative results from public and private elementary schools. J Acad Nutr Diet. 2012; 112(9): 1380-1389. [PubMed: 22673797]

48. Harris, JL.; Schwartz, MB.; Brownell, KD. Rudd Center for Food Policy and Obesity; 2010. Fast food FACTS: evaluating fast food nutrition and marketing to youth. http:// www.fastfoodmarketing.org/media/FastFoodFACTS_Report.pdf [Accessed December 2010]

49. Serrano EL, Jedda VB. Comparison of fast-food and non-fast-food children's menu items. J Nutr Educ Behav. 2009; 41(2):132-137. [PubMed: 19304259]

50. McDonald's USA. [Accessed December 2012] Commitments to Offer Improved Nutrition Choices. Jul 26. $2011 \mathrm{http} / / / \mathrm{www}$.aboutmcdonalds.com/mcd/newsroom/press_releases/ corporate_news_archive.html

51. Arby's Foundation Inc. [Accessed December 2012] Arby's introduces new kids meal and partners with Share Our Strength's No Kid Hungry Campaign to help end childhood hunger. 2011. http:// www.prnewswire.com/news-releases/arbys-introduces-new-kids-meal-and-partners-with-shareour-strengths-no-kid-hungry-campaign-to-help-end-childhood-hunger-130710038.html

52. National Restaurant Association. [Accessed December 2012] Kids LiveWell. http:// www.restaurant.org/foodhealthyliving/kidslivewell/about/

53. Bornhorst C, Huybrechts I, Ahrens W, et al. Prevalence and determinants of misreporting among European children in proxy-reported $24 \mathrm{~h}$ dietary recalls. Br J Nutr. 2012:1-9. 
54. Burrows TL, Martin RJ, Collins CE. A systematic review of the validity of dietary assessment methods in children when compared with the method of doubly labeled water. J Am Diet Assoc. 2010; 110(10):1501-1510. [PubMed: 20869489]

55. Briefel RR, Wilson A, Gleason PM. Consumption of low-nutrient, energy-dense foods and beverages at school, home, and other locations among school lunch participants and nonparticipants. J Am Diet Assoc. 2009; 109(2 Suppl):S79-90. [PubMed: 19166676]

56. Taber DR, Chriqui JF, Chaloupka FJ. Differences in nutrient intake associated with state laws regarding fat, sugar, and caloric content of competitive foods. Arch Pediatr Adolesc Med. 2012; 166(5):452-458. [PubMed: 22566546] 


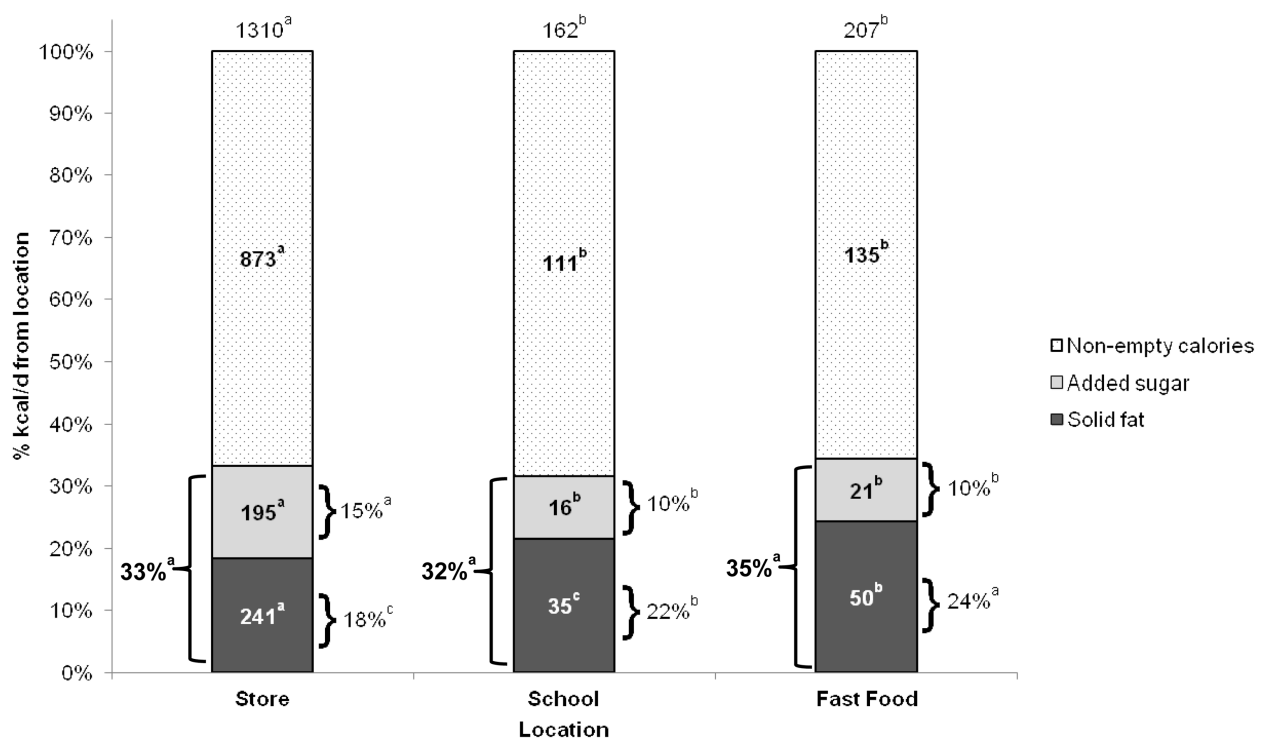

Figure 1.

Percentage of per capita energy intake from each location provided by empty calories, added sugar, and solid fat among US children aged 2-18 years, 2009-2010 ${ }^{\mathrm{a}}$

aData for children and adolescents aged 2-18 years from the National Health and Nutrition Examination Survey (NHANES) 2009-2010. Sample sizes: Total sample $(n=3,077)$, Store consumers $(n=3,040)$, School consumers $(n=697)$, and Fast food consumers $(n=1,035)$. Empty calories are calculated as the sum of energy from added sugar and solid fat. Pairwise $t$ tests compared locations. Values without a common letter are significantly different, $\mathrm{p}<0.05$ with Bonferroni correction.

Numbers above bars indicate per capita total energy intake from each location calculated including the entire sample, both consumers and non-consumers from each location (All locations1,907 kcal; Restaurants $90 \mathrm{kcal}$; Other locations $137 \mathrm{kcal})$. Among consumers at each location: Store 1,324 kcal; School 670 kcal; Fast food 655 kcal; Restaurant 743 kcal; Other $391 \mathrm{kcal}$. Numbers within bars indicate per capita energy intake from non-empty calories, added sugar, or solid fat from each location (calculated including the entire sample, both consumers and non-consumers from each location). Percentages indicate the percentage of kilocalories per day $(\% \mathrm{kcal} / \mathrm{d})$ from empty calories (to left of bar) and from added sugar and solid fat (to the right of bar) from each location. 


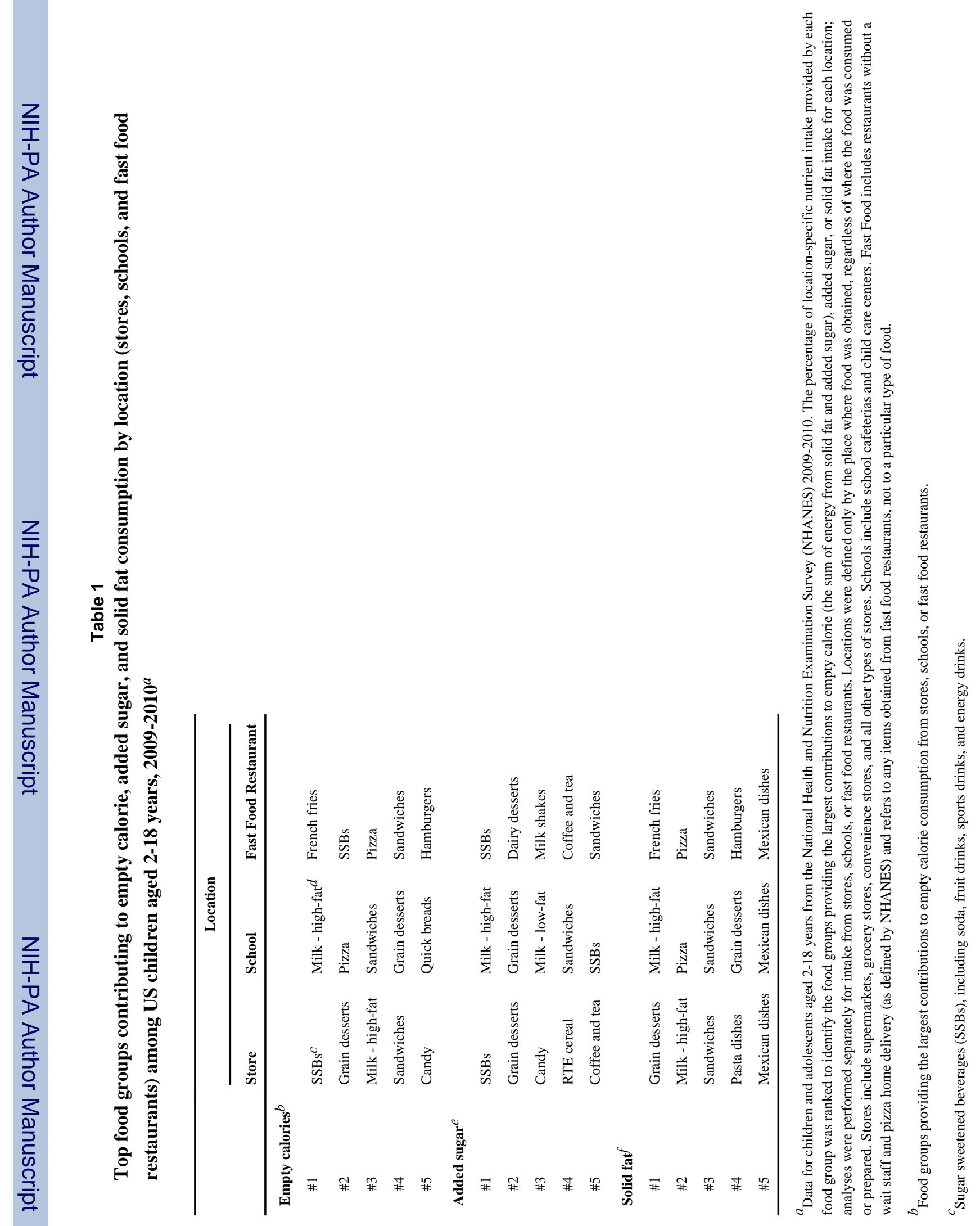




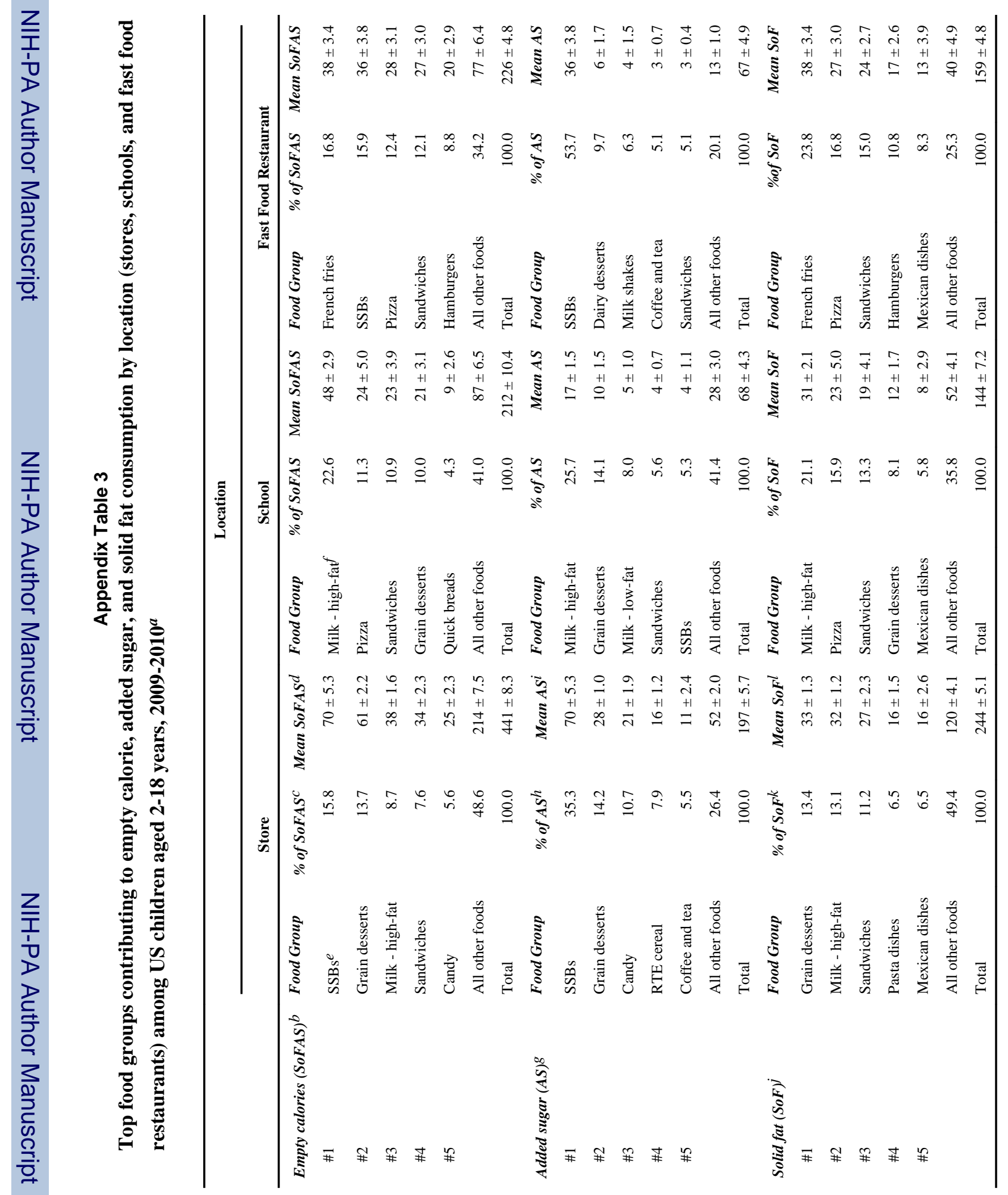




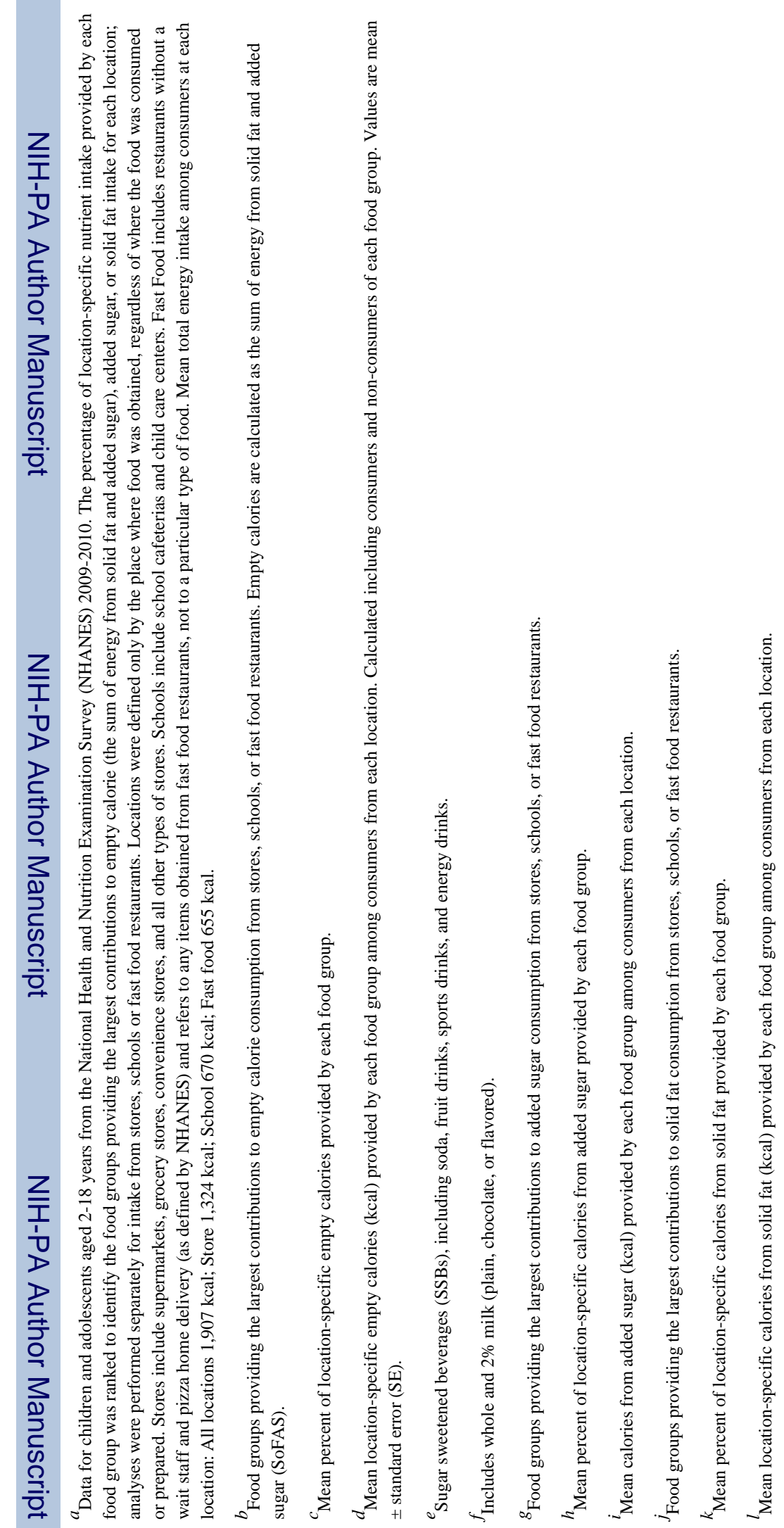

